\title{
Investigating the effect of behavioral and demographic characteristics of Iranian women on the number of children ever born
}

\author{
Maryam Seyedtabib ${ }^{1}$, Hossein Mahjub², Mahmood Mahmoudi ${ }^{3}$ Abbas Moghimbeigi ${ }^{4 * \mathbb{D}}$
}

Received: 24 Sep 2020

Published: 22 Mar 2021

\section{Abstract}

Background: The number of children ever born (CEB) to a woman, as an index of her fertility behavior, are interesting for the governments and demographer policymakers. In recent years, a notable reduction of fertility and population aging in Iran has caused concern among politicians, and it has led to starting new changes in demographic policies. Therefore, to adopting new demographic and health policies programs, identification of factors that affecting CEB is essential.

Methods: To evaluate determinant factors on CEB, information of 20093 married Iranian women aged between 15 and 54 years has been analyzed from the Iranian National Institute of Health Research survey. Based on the structure of data and the possible influential unobserved population heterogeneity on CEB in each city and province, a multilevel count regression model was applied. The analysis was performed using the ' $\mathrm{R}$ ' software (version 3.5) with a significant level of 0.05 .

Results: Findings show that the mean and median number of CEB was 2.82 and 2.00 for all women, respectively. Meanwhile, these values were 4.56 and 4.00 for the women who reached menopause. There was a significant unobserved heterogeneity affecting CEB in each province $\left(\sigma_{\mathrm{p}}=0.018\right)$. Also, the results of the multilevel model show that living in an urban area $(\mathrm{RR}=0.90)$, higher age at first marriage $(R R=0.96)$, higher education $(R R=0.84, R R=0.81)$, and exposure to mass media $(R R=0.87)$ decrease the risk ratio of the number of CEB $(\mathrm{p}<0.001)$.

Conclusion: It seems that the tendency of women to academic education and their access to mass media has a significant effect on reducing childbearing. Therefore, in future planning, attention to these two factors can be useful and helpful to move to increase fertility.

Keywords: Fertility, Multilevel Analysis, Count Response, Children ever Born

Conflicts of Interest: None declared

Funding: Hamadan University of Medical Sciences

\section{*This work has been published under CC BY-NC-SA 1.0 license.}

Copyright $₫$ Iran University of Medical Sciences

Cite this article as: Seyedtabib M, Mahjub H, Mahmoudi M, Moghimbeigi A. Investigating the effect of behavioral and demographic characteristics of Iranian women on the number of children ever born. Med J Islam Repub Iran. 2021 (22 Mar);35:38. https://doi.org/10.47176/mjiri.35.38

\section{Introduction}

Fertility is one of the most important indicators of population growth and hence is always of interest for demographers and population planners (1). In the demography concepts, fertility refers to 'the actual production of a child $(2,3)$.

Corresponding author: Dr Abbas Moghimbeigi, moghimb@yahoo.com

1. Department of Biostatistics \& Epidemiology, School of Public Health, Hamadan University of Medical Sciences, Hamadan, Iran

2. Department of Biostatistics \& Epidemiology, School of Public Health and Research Center for Health Sciences, Hamadan University of Medical Sciences, Hamadan, Iran

3. Department of Health Services, Science and Research Branch, Islamic Azad University, Tehran, Iran

4. Department of Biostatistics and Epidemiology, School of Health, Research Center for Health, Safety and Environment, Alborz University of Medical Sciences, Karaj, Iran
Over the past five decades, economic and social development, reduced fertility, and increasing life expectancy led to substantial changes in the world population structure (4).

Studies on fertility and reproductive health have been

\section{$\uparrow$ What is "already known" in this topic:}

The number of Children Ever Born (CEB) depends on several important factors such as biological, behavioral, and socioeconomic factors, which can have a positive or negative significant effect. It was recognized that not only community characteristics but also the women characteristics could influence women's childbearing.

$\rightarrow$ What this article adds:

It seems that age at first marriage, public mass media, and higher education had more effective on reduction of $\mathrm{CEB}$ which must be considered in the planning of increasing fertility in the future. 
undertaken in different countries (5-7). Studies showed that the decline in fertility has dramatically increased, and this reduction was below replacement levels in some countries (8-10). Based on the studies, the increase in age at first marriage and an increased proportion of women who never intend to marry has led to a decline in the fertility rate (11-14). Findings of a study showed that the marriage postponement by the age group of 18-26 years had a notable influence on the change in the total fertility rate (15). Also, the importance of education as an influential factor on reproductive behavior and fertility was also confirmed (16). According to studies, nowadays childbearing is being postponed until accomplishing desired levels of education or professional stability $(17,18)$.

On the other hand, the difference between fertility levels in developed and developing societies refers to the socioeconomic activities of women (19). In the past, women were more focused on family and participated less in social activities, and so they contributed positively to fertility rates $(19,20)$.

Nowadays, the rapid decline in fertility rates is one of the main demographic concerns in Iran smiliar to many other countries (21). Fertility rates have been changed in Iranian families over the last few decades. According to historical data, between 1976 and 1986, the population of Iran increased from 33.3 to 49.4 million (22). Following this dramatic increase, the government and policymakers decided to control the population through the family planning system. Based on the census records in 2011, the total fertility rate of Iran was 1.85 with a total population of $75,149,669(23,24)$. In recent years, the decline in woman's fertility rate has led to some changes by the Ministry of Health to prevent further population decline and encourage population growth (25). To implement new changes, it is necessary to identify the factors affecting fertility decline.

The number of children ever born (CEB) to a woman is one of the fertility determinant indices, which influences population growth $(26,27)$. That is also an index of the woman's general fertility behavior (28).

The number of CEB depends on several important factors such as biological, behavioral, and socioeconomic factors, which can have either a positive or negative significant effect on CEB (29-31). It was recognized that not only community characteristics but also the women characteristics could influence women's childbearing (32)

Thus, in this study, we will evaluate the main sociodemographic characteristics of women affecting the number of CEB as an index of fertility. Meanwhile, attention to cultural differences in various ethnic groups is essential. Based on the studies, fertility intentions vary among religions and races (33-35). The multi-ethnic society in Iran has led to cultural variation that may affect fertility. Thus, sampling design, as well as the heterogeneity of unobserved factors such as cultural factors in different regions, justifies the use of multilevel models in the evaluation of data $(2,36,37)$. Also, considering the type of response variable, namely the number of CEB, Poisson and Negative Binomial (NB) distributions will be used.

\section{Methods}

\section{Study design and data}

The data used for this study was extracted from the Iranian household 2010-2011 survey. The survey was a cross-sectional multi-stage stratified cluster-random study that had been conducted by the Iranian National Institute of Health Research, Ministry of Health and Medical Education. Because the population size is different among different provinces of Iran, the sampling was conducted proportional to population size in each district within each province in the survey. More detail about the survey as well as sampling design are available in Rashidian et al. (38). Among nearly 35084 women aged 15-54 (no marriage $=9394$, at least one marriage $=25690$ ) in the survey, only women who had been married for more than 5 years were considered for investigation in this study. The response rate was $98.0 \%$. Finally, 20093 (57.27\% in the survey) married women with complete data for the selected variable were included in the investigation. Thirty-one provinces and their cities also used in the study. The number of women for provinces varied between 252 and 3138 in the included data.

The information for the women had gathered through Iran Demographic and Health Surveys (IDHS) questionnaire's women. The information in the questionnaire included women's characteristics, marriage and cohabitation, fertility history, child mortality, contraceptive use, etc.

\section{Statistical method}

The main distributions, such as Negative Binomial (NB) and Poisson distributions (shown below) have been used to evaluate the count response variable $(37,39)$. When the mean and variance of the count distribution are the same, the use of Poisson distribution is appropriate. Meanwhile, increasing variance to mean (over-dispersion) results in the use of NB distribution. If there is significant overdispersion in the distribution of the count response, the estimates from the NB regression model are consistent and correct (40).

In this study, the response variable is CEB that refers to the woman's number of children ever born who were living up to the time of the Iranian Multiple Indicators Demographic and Health Survey (IrMIDHS). The following are two Poisson and binomial distributions;

$$
\begin{aligned}
& \text { The NB distribution: } \\
& \begin{aligned}
p(Y=y)=\frac{\Gamma(y+r)}{\Gamma(r) \Gamma(y+1)} p^{r}(1-p)^{y} \quad y=0,1,2,3, \ldots \\
\qquad p=\frac{r}{r+\mu}
\end{aligned}
\end{aligned}
$$

In the NB distribution, $\mu$ and $\mathrm{r}$ are the mean and the dispersion parameters, respectively. The $r^{1}$ is the overdispersion parameter and when $r^{-1} \rightarrow 0$, the NB distribution is approximated by Poisson distribution as follow:

$$
p(Y=y)=\frac{e^{-\lambda} \lambda^{y}}{y !} \quad y=0,1,2,3, \ldots .
$$

On the other hand, the hierarchical structure of data which is gathered at different levels of province and city, allows the use of a multilevel model (36). Ignoring the heterogeneity underestimates the standard error of coefficients and lead to incorrect inferences (41). 
Thus, the multilevel NB and Poisson distributions used in this study as follows:

$$
\begin{aligned}
& \log \left[\mu_{i j k}\right]=\gamma_{i j k}=b_{i j k}^{T} \beta+u_{i}+v_{i j} \\
& i=1, \ldots, 31 \quad j=1, \ldots, 339 \quad k=1, \ldots, 20093
\end{aligned}
$$

where $\mu_{i j k}$ is the expected number of CEB. The term $b_{i j k}^{T}$ is the vector of covariates for the $\mathrm{k}^{\text {th }}$ woman in the $\mathrm{j}^{\text {th }}$ city that nested within the $\mathrm{i}^{\text {th }}$ province and $\beta$ refers to the regression coefficient vector in the model. The parameter of $u_{i}$ is random effect for the province $\mathrm{i}$ and $v_{i j}$ is random effect for city $\mathrm{j}$ in the province $\mathrm{i}$.

In the multilevel model (3), woman was the first-level that nested within the city, i.e. second-level, and each city nested within the third-level, namely province.

For data analysis, both multilevel Poisson and NB models were implemented. These two models were investigated separately for the group of women that reached the age of menopause and for all the women as a whole (15-54 years). The calculation was performed within the ' $R$ ' software, version 3.5. The Newton-Raphson algorithm was used to estimate the parameters and random effect components $\left(u_{i}\right.$ and $\left.v_{i j}\right)$.

The results of the multilevel models were reported in terms of $\beta$ and risk ratio (RR). RR is the ratio of the probability of an outcome in an exposed group to the probability of an outcome in an unexposed group which calculated as $\operatorname{Exp}(\beta)$. A risk ratio $(\mathrm{RR})$ less than one means a lower chance of having a child $\left(\mu_{i j k}\right)$ compared to the reference group. Also, a RR greater than one means a greater chance of having a child compared to the reference group.

Some biological and socio-demographic factors were used in the model. The importance of these factors, including age at first marriage, abortion, contraceptive use, as well as some socio-demographic factors such as education, employment status, income, and access to mass media has been established in earlier studies $(21,42-45)$.

Considering the time of survey, three levels of income including, less than US\$600 (Low), US\$600-1100 (Middle) and more than US\$1100 (High) were considered (income of man and woman). Also, the use of public mass media refers to only three media: radio, newspaper, and magazine that the women used at least one of them daily or weekly.

\section{Results}

The mean (SD) number of CEB in rural areas is 3.20 (2.12) and 2.65 (1.70) for urban areas. Around 51.5\% of children were sons and $48.5 \%$ were girls. The minimum and maximum mean (median) of CEB is 2.35 (2.00) and 4.14 (4.00) for Mazandaran and Sistan-Baluchestan provinces, respectively (Table 1). These values were 2.82 (2.00) and 4.56 (4.00) for all the women and the women who reached menopause, respectively.

\begin{tabular}{|c|c|c|c|c|c|}
\hline \multirow[t]{2}{*}{ Province } & \multirow[t]{2}{*}{ No of cities } & \multirow[t]{2}{*}{ No of women } & \multicolumn{3}{|c|}{ No of children } \\
\hline & & & Mean & Median & IQR \\
\hline East Azarbaijan & 19 & 1063 & 2.62 & 2.00 & 2.00 \\
\hline West Azarbaijan & 14 & 795 & 2.92 & 2.00 & 2.00 \\
\hline Ardabil & 9 & 311 & 3.05 & 3.00 & 2.00 \\
\hline Isfahan & 21 & 1495 & 2.60 & 2.00 & 2.00 \\
\hline Ilam & 7 & 252 & 3.21 & 3.00 & 2.00 \\
\hline Bushehr & 9 & 263 & 3.09 & 3.00 & 2.00 \\
\hline Tehran & 13 & 3138 & 2.45 & 2.00 & 2.00 \\
\hline Chaharmahal Bakhtiari & 6 & 263 & 3.10 & 3.00 & 3.00 \\
\hline South Khorasan & 7 & 250 & 3.21 & 3.00 & 2.00 \\
\hline Razavi Khorasan & 19 & 1563 & 2.81 & 2.00 & 2.00 \\
\hline North Khorasan & 6 & 256 & 3.17 & 3.00 & 2.00 \\
\hline Khozestan & 20 & 1042 & 3.42 & 3.00 & 3.00 \\
\hline Zanjan & 7 & 265 & 2.81 & 2.00 & 3.00 \\
\hline Semnan & 4 & 268 & 2.47 & 2.00 & 2.00 \\
\hline Sistan and Baluchestan & 10 & 554 & 4.14 & 4.00 & 4.00 \\
\hline Fars & 24 & 1179 & 2.80 & 2.00 & 2.00 \\
\hline Qazvin & 5 & 333 & 2.66 & 2.00 & 1.00 \\
\hline Qom & 1 & 289 & 2.84 & 2.00 & 2.00 \\
\hline Kordistan & 9 & 390 & 2.94 & 3.00 & 2.00 \\
\hline Kerman & 16 & 649 & 3.29 & 3.00 & 2.00 \\
\hline Kermanshah & 14 & 488 & 2.95 & 2.00 & 2.00 \\
\hline Kohgiluyeh and Boyer_ahmad & 5 & 286 & 3.67 & 3.00 & 3.00 \\
\hline Golestan & 11 & 439 & 2.82 & 2.00 & 2.00 \\
\hline Gilan & 16 & 691 & 2.39 & 2.00 & 2.00 \\
\hline Lorestan & 9 & 421 & 3.08 & 3.00 & 2.00 \\
\hline Mazandaran & 16 & 1035 & 2.35 & 2.00 & 2.00 \\
\hline Markazi & 10 & 388 & 2.60 & 2.00 & 2.00 \\
\hline Hormozgan & 11 & 361 & 3.55 & 3.00 & 3.00 \\
\hline Hamadan & 8 & 480 & 2.73 & 2.00 & 3.00 \\
\hline Yazd & 10 & 297 & 2.63 & 2.00 & 2.00 \\
\hline Alborz & 3 & 589 & 2.44 & 2.00 & 2.00 \\
\hline Total & 339 & 20093 & 2.82 & 2.00 & 2.00 \\
\hline
\end{tabular}

Table 1. Number of cities, women, and descriptive statistics of children in different province, $\mathrm{N}=20093$ 


\begin{tabular}{|c|c|c|}
\hline \multirow[t]{2}{*}{ Women's characteristics } & $\begin{array}{c}\text { Menopausal } \\
\text { women }\end{array}$ & All women \\
\hline & No. $(\%)$ & No. $(\%)$ \\
\hline \multicolumn{3}{|l|}{ Current Age } \\
\hline$\leq 20$ & $0(0.0)$ & $130(0.6)$ \\
\hline$(20-30]$ & $0(0.0)$ & $4914(24.5)$ \\
\hline$(30-40]$ & $7(0.7)$ & $7278(36.2)$ \\
\hline$>40$ & $1007(99.3)$ & $7771(38.7)$ \\
\hline \multicolumn{3}{|l|}{ Education } \\
\hline Less than high school & $855(84.3)$ & $1517675.5)$ \\
\hline High school & $115(11.3)$ & $3263(16.2)$ \\
\hline University & $44(4.4)$ & $1654(8.23)$ \\
\hline \multicolumn{3}{|l|}{ Contraceptive use } \\
\hline Yes & $0(0.0)$ & $11337(56.4)$ \\
\hline No & $1014(100.0)$ & 8755 (43.6) \\
\hline \multicolumn{3}{|l|}{ Abortion/ Stillbirth } \\
\hline Yes & $282(27.8)$ & 4938 (24.6) \\
\hline No & $732(72.2)$ & $15155(75.4)$ \\
\hline \multicolumn{3}{|l|}{ Age at first marriage } \\
\hline$<15$ & $127(12.5)$ & $2215(11.0)$ \\
\hline$[15-20)$ & $530(52.3)$ & $10419(51.8)$ \\
\hline$[20-25)$ & $284(28.0)$ & $5759(28.7)$ \\
\hline$[25-30)$ & $52(5.1)$ & $1381(6.9)$ \\
\hline$[30-35)$ & $14(1.4)$ & $263(1.3)$ \\
\hline$\geq 35$ & $7(0.7)$ & $56(0.3)$ \\
\hline \multicolumn{3}{|l|}{ Employment status } \\
\hline Housewife & $926(91.3)$ & $18321(91.2)$ \\
\hline Employed & $88(8.7)$ & $1772(8.8)$ \\
\hline \multicolumn{3}{|l|}{ Use of public mass media } \\
\hline Yes & $468(46.2)$ & $12180(60.6)$ \\
\hline No & $546(53.8)$ & $7913(39.4)$ \\
\hline \multicolumn{3}{|l|}{ Family's income } \\
\hline Low & $782(77.1)$ & $15939(79.3)$ \\
\hline Middle & $196(19.3)$ & $3531(17.6)$ \\
\hline High & $36(3.6)$ & $623(3.1)$ \\
\hline \multicolumn{3}{|l|}{ Area of residence } \\
\hline Rural & $313(30.9)$ & $5956(29.6)$ \\
\hline Urban & $701(69.1)$ & $14137(70.4)$ \\
\hline Total & 1014 & 20093 \\
\hline
\end{tabular}

or equal 20 years and $38.7 \%$ were over 40 years of age. It was found that the first marriage for the most women happened between 15 and 20 years $(51.8 \%)$, followed by 20 25 years of age $(28.7 \%)$. Most of the women were housewives and only $8.8 \%$ of women were employed. Nearly $25.0 \%$ of had had at least one abortion or stillbirth. Around $16.2 \%$ of women had a high school and $8.2 \%$ had an academic education. In menopausal group, the percentage of women with academic education was 4.4. Also, the percentage of women with middle and high family income were $18.0 \%$ and $3.1 \%$, respectively. The majority of women $(60.6 \%)$ used at least one of public mass media such as radio, newspapers and magazines, and $34.9 \%$ of the women did not use any of them. These values were $46.2 \%$ and $53.8 \%$ for menopausal women, respectively. Findings also show about $43.6 \%$ of women did not use any of the contraceptive methods within their time of pregnancies, whereas, other women stated that they had used at least one method of contraceptive.

The findings in Table 3 show that nearly $4 \%$ of women had no child, $20 \%$ of women had one child, and $27.8 \%$ of them had four children or more. It was found that only $2 \%$ of women over 40 years of age had no child, whereas $54.9 \%$ of them had four or more children. Among the women who had had academic education, only $3.3 \%$ had four or more children. Most of them had one (39.7\%) or two $(39.5 \%)$ children.

Considering women's pregnancy intentions in future, around $63.0 \%$ of women stated that they did not decide to have more child, while the average of the CEB for them

Table 2 shows that nearly $0.6 \%$ of women were below was 3.18 . Nearly $13.7 \%$ of women with an average of

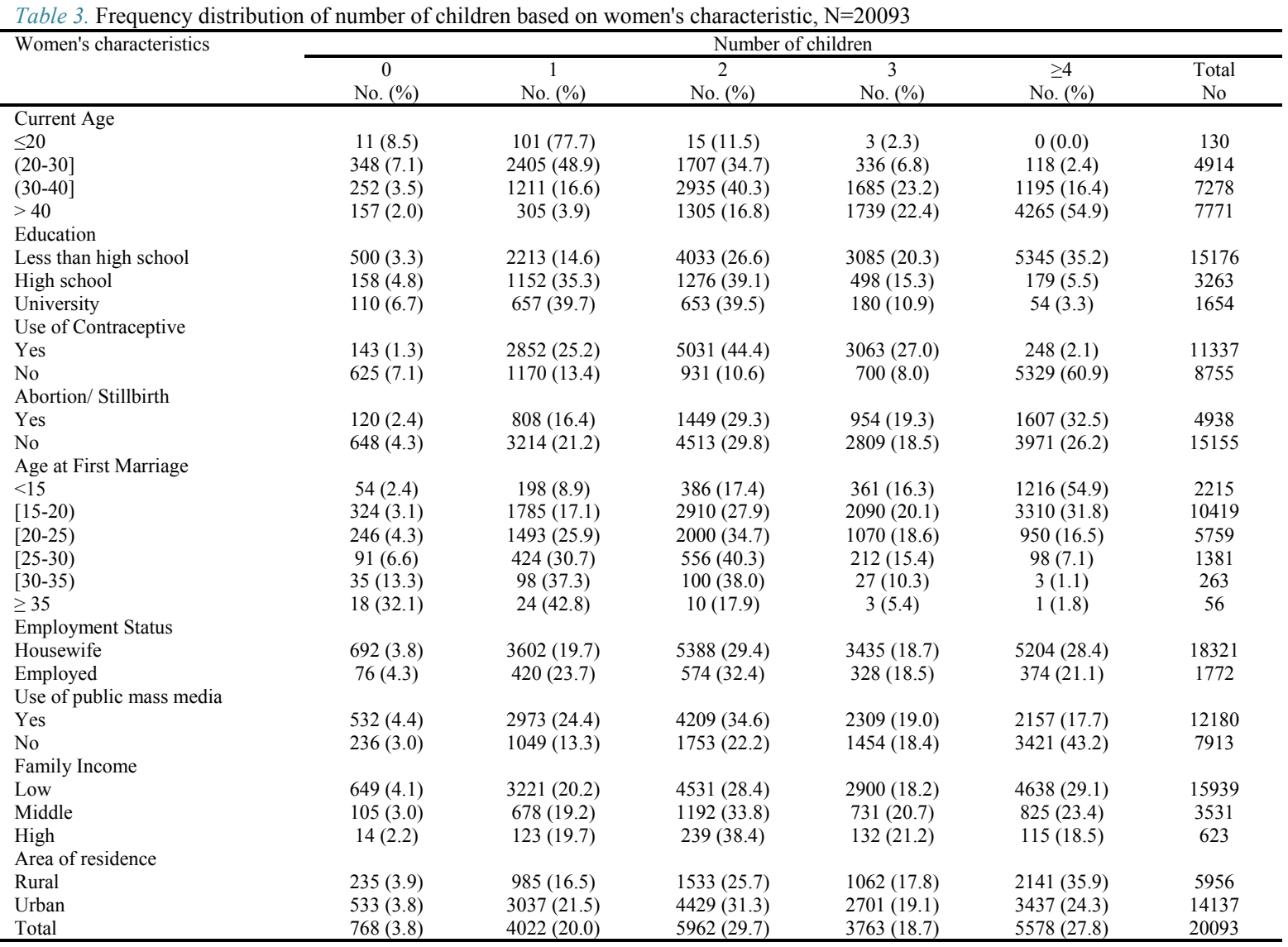


3.45 for the CEB stated that they could not get fertility. These findings are presented in Table 4.

The average CEB based on the women's age and the duration of their marriage has been shown in Table 5. The average CEB for the women over 50 years age who have been married at least 30 years is 5.11. Also, women who have passed exactly 5 years of their marriage had on average 1.04 CEB.

Data analysis were performed for multilevel Poisson and NB models. Based of significant over- dispersion ( $r=0.031, p<0.001$ all women, $r=0.010, p<0.001$ menopau- sal women) the multilevel NB model was considered. Results are summarized in Table 6.

The frequency and expected of CEB from the model was presented in Figure 1. Some independent variables were significantly related to the estimated mean number of CEB. As will be discussed in details below, living in urban areas, higher age at first marriage, higher education and the use of public mass media have reduced the risk ratio (RR) of the expected CEB in the whole country, as well as, the menopausal women $(\mathrm{p}<0.001)$.

Higher education has a negative influence on the ex-

Table 4. The average number of children in different Iranian women's age group based on future planning for pregnancy, $\mathrm{N}=20093$

\begin{tabular}{|c|c|c|c|c|c|c|c|c|c|c|}
\hline \multirow[b]{2}{*}{ Group } & \multicolumn{10}{|c|}{ Exact age of women } \\
\hline & $15-19$ & $20-24$ & $25-29$ & $30-34$ & $35-39$ & $40-44$ & $45-49$ & $50-54$ & Total & No. of Women (\%) \\
\hline $\mathrm{I}$ & 0.98 & 1.07 & 1.23 & 1.47 & 1.74 & 2.01 & 2.52 & 2.00 & 1.37 & $3495(17.4)$ \\
\hline II & 1.36 & 1.63 & 1.88 & 2.27 & 2.84 & 3.37 & 4.24 & 5.08 & 3.18 & $12668(63.1)$ \\
\hline III & 0.50 & 0.53 & 0.91 & 1.34 & 2.13 & 2.70 & 3.64 & 4.48 & 3.45 & $2759(13.7)$ \\
\hline IV & & 1.25 & 1.49 & 1.73 & 2.16 & 2.58 & 3.36 & 5.25 & 1.74 & $1171(5.8)$ \\
\hline Total & 1.05 & 1.23 & 1.53 & 1.98 & 2.63 & 3.22 & 4.08 & 4.78 & 2.82 & \\
\hline $\begin{array}{l}\text { No. of women } \\
(\%)\end{array}$ & $\begin{array}{c}55 \\
(0.3)\end{array}$ & $\begin{array}{l}1135 \\
(5.6)\end{array}$ & $\begin{array}{c}3087 \\
(15.4)\end{array}$ & $\begin{array}{c}3727 \\
(18.5)\end{array}$ & $\begin{array}{c}3597 \\
(17.9)\end{array}$ & $\begin{array}{c}3186 \\
(15.9)\end{array}$ & $\begin{array}{c}2932 \\
(14.6)\end{array}$ & $\begin{array}{c}2374 \\
(11.8)\end{array}$ & & 20093 \\
\hline
\end{tabular}

I: They want to have another child II: They do not want to have another child

III: They cannot be pregnant $\quad$ IV: They do not have any plan for future

Table 5. Number of children by specified duration of marriage and age cohort for Iranian women, $\mathrm{N}=20093$

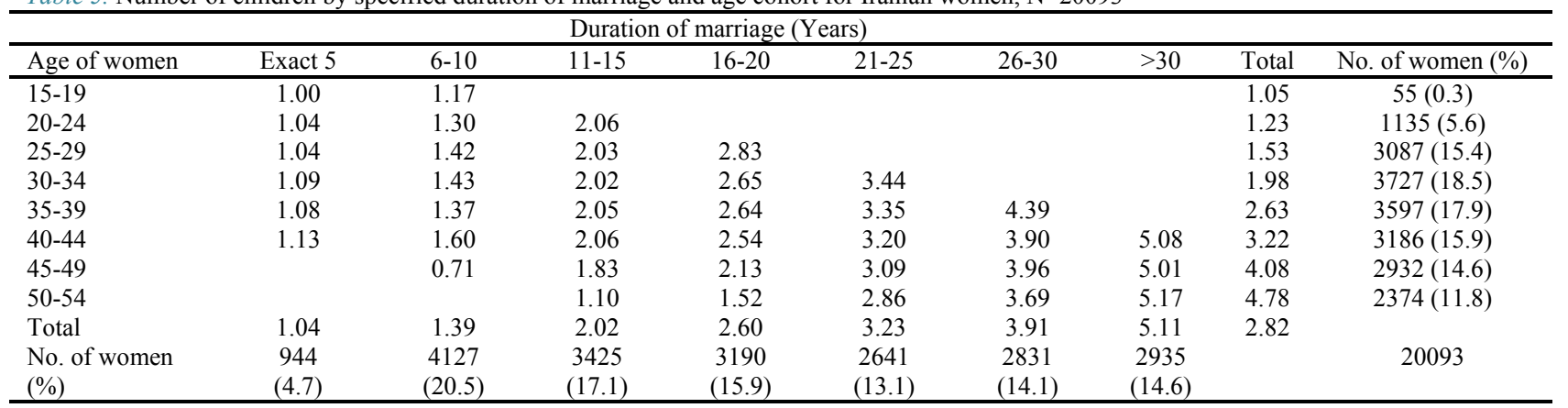

Table 6. Result of multilevel NB regression model analysis for the number of children ever born

\begin{tabular}{|c|c|c|c|c|}
\hline \multirow{3}{*}{$\begin{array}{l}\text { Variable } \\
\text { Group }\end{array}$} & \multicolumn{4}{|c|}{ Multilevel NB regression model } \\
\hline & \multicolumn{2}{|r|}{ All women } & \multicolumn{2}{|c|}{ Menopausal women } \\
\hline & Beta & $\mathrm{RR}(\mathrm{CI})$ & Beta & $\mathrm{RR}(\mathrm{CI})$ \\
\hline Current Age & 0.039 & $1.040(1.038-1.042)^{* * *}$ & 0.026 & $1.026(1.014-1.038)^{* * *}$ \\
\hline Age at First Marriage & -0.043 & $0.958(0.956-0.960)^{* * *}$ & -0.042 & $0.959(0.951-0.966)^{* * *}$ \\
\hline Area of residence (Ref., Rural) & - & - & - & - \\
\hline Urban & -0.107 & $0.899(0.883-0.915)^{* * *}$ & -0.154 & $0.857(0.805-0.913)^{* * *}$ \\
\hline Education (Ref., <High School) & - & - & - & - \\
\hline High school & -0.178 & $0.837(0.813-0.862)^{* * *}$ & -0.254 & $0.776(0.684-0.879)^{* * *}$ \\
\hline University & -0.206 & $0.814(0.779-0.850) * * *$ & -0.262 & $0.770(0.630-0.940)^{*}$ \\
\hline Use of public mass media (Ref., No) & - & - & - & - \\
\hline Yes & -0.141 & $0.868(0.853-0.884)^{* * *}$ & -0.147 & $0.863(0.809-0.921)^{* * *}$ \\
\hline Employment status (Ref., Housewife) & - & - & - & - \\
\hline Employed & -0.046 & $0.955(0.926-0.985)^{* *}$ & 0.002 & $1.002(0.903-1.112)$ \\
\hline Family Income (Ref., Low) & - & - & - & - \\
\hline Middle Income & 0.002 & $1.002(0.950-1.056)$ & -0.080 & $0.923(0.849-1.004)$ \\
\hline High Income & 0.043 & $1.044(1.020-1.069)$ & -0.120 & $0.887(0.725-1.085)$ \\
\hline Abortion/stillbirth (Ref., No) & - & - & - & - \\
\hline Yes & -0.001 & $0.999(0.980-1.019)$ & 0.012 & $1.012(0.949-1.080)$ \\
\hline Use of contraceptives (Ref., No) & - & - & - & - \\
\hline Yes & -0.158 & $0.854(0.839-0.879) * * *$ & - & - \\
\hline Sigma (Province) & & $0.018(0.005)^{* *}$ & & $0.013(0.006)^{* *}$ \\
\hline Sigma (City) & & $0.006(0.001)^{*}$ & & $0.001(0.004)$ \\
\hline $\mathrm{N}$ & & 20093 & & 1014 \\
\hline
\end{tabular}




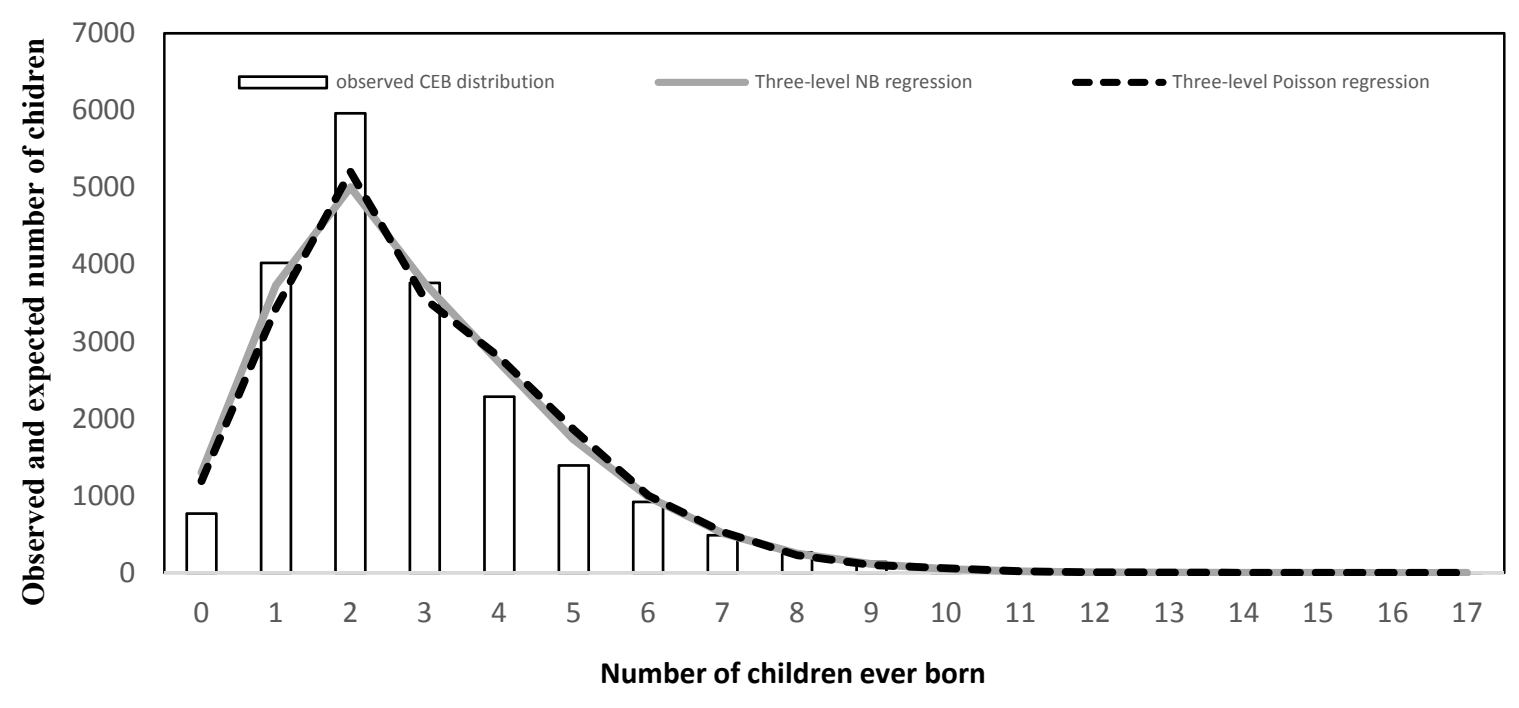

Fig. 1. Distributions of CEB, and expected number of children based on multilevel Poisson and NB regression model.

pected number of CEB. In other word, women with higher education had fewer children than women with less education $(\mathrm{p}<0.001)$. Higher age at first marriage was associated with a decreased risk ratio of CEB in the whole country and the menopausal group of women $(\mathrm{p}<0.001)$.

The risk ratio of CEB among women who did not use contraceptives were greater than among those who did use them. In other words, the risk ratio of CEB in women with at least one contraceptive use was $(R R=0.854, p<0.001)$.

Results show that women in urban areas had fewer children than women in rural areas. This finding has been concluded for all women $(\mathrm{RR}=0.899, \mathrm{p}<0.001)$, as well as for menopausal women $(R R=0.857, p<0.001)$. In the whole country the employed women had lower risk ratio of CEB than the Housewife women $(R R=0.955, p<0.001)$.

Our findings showed that there were some unobserved heterogeneity in different provinces that affected the expected number of CEB in the whole country and in menopausal group. Also, there was significant unobserved factors affect the expected number of children in each city in total country $(\mathrm{p}<0.001)$.

\section{Discussion}

This study evaluated the determinants on the number of children ever born (CEB) as a fertility behavior on Iranian women using multilevel Negative Binomial regression model.

The study found that majority of women had had one or two children. Meanwhile, the mean number of CEB to women with marriage history more than 20 years was reported 4.03. Among the factors influencing the number of CEB, women's education, contraceptive use, and use of mass media were found to be most effective. The importance of women's education on fertility and number of CEB was demonstrated in many previous studies $(46,47)$.

Increasing education is also associated with an increase in the age of first marriage (48). The rising age of first marriage for women and contraceptive use have been no- ticed the indicators of low fertility behavioral (14). Age of the first marriage is the one most determinants effective on the number of CEB (44). At older ages, the probability of conception decreases. Higher age of marriage reduces probability of a healthy fertility, so fertility decreases (49). The negative effect of high age of marriage for women on the expected CEB was also found in the present study. Another main factor in our findings was the role of contraceptive use in decreasing the expected number of children which were found in the others studies $(21,50)$. Some studies showed higher level of contraceptive use leading to fertility reduction $(5,51)$.

It seems the family planning policies have been well implemented in Iran for two past decades (51) and in the long run, the implementation of family planning service has had a significant effect on fertility decline in Iran (9).

Increasing the prevalence of contraceptive use could also be a result of improved women's education. Higher education has a negative influence on fertility $(21,52)$. Iranian women usually postpone their fertility period until they complete their education or obtain the right job (21). Erfani and McQuillan (2014) showed the rapid fertility decline among highly educated women was greater than less-educated women (53). The findings of our study also showed that the increasing education of women was correlated with reduced expected number of children $(46,53)$ Based on conducted studies, the place of residence can affect childbearing or the number of CEB by a woman $(54,55)$. Usually, the number of children in rural areas is more than urban areas which were also found in our results $(8,56)$. Employed or higher-educated women are more likely to live in urban (57). On the other hand, less access to contraceptives in rural areas compared to rural areas may lead to an increased number of children in these areas. So, living in urban areas may indirectly influence the number of children (2).

Although abortion or stillbirth is the common events in the process of fertility, the reaction to them occurs differently in different women. In some cases, the tendency to 
have a child and in some cases, the inability to reach the successful fertility, affects the subsequent pregnancies (58). Nonetheless, the findings of our study showed these events had no significant effect on the estimated mean of CEB.

The relationship between women's social achievement and their fertility dynamics has been observed (13). Some studies have shown that the tendency of women to personal independence through their education and work before motherhood can affect the number of children $(49,59)$. Its effect has also observed in this study. One of the other most important factors was the role of mass media on a decline in the number of children. A study by Barber and Axinn has shown there is a relation between fertility and exposure to public mass media (60). This result also has indicated in another study by Hornik and McAnany (61). Based on studies, the public media had greatly contributed to increase knowledge about fertility health, contraceptive use, family planning programmes, and family size decline $(8,62,63)$.

In the end, it is worth mentioning that, although the high sample size could affect the significance of the variable $(p<0.05)$ in this study, the main purpose was evaluating the direction of effects, namely increasing or decreasing, on the number of CEB.

\section{Conclusion}

Finally, it is noted that success in implementing any new planning to population structure requires awareness of the current economic and social conditions of the country.

According to the role of the media in the past in Iran, it is still expected that media play the main role in implementing new policies toward increasing fertility. The best period of time for fertility, as well as the consequences of population decline and aging population, can be taught by mass media. Creating incentives packages can also help increase fertility, especially among educated women.

\section{Acknowledgments}

The authors are grateful to the Iranian National Institute for Health Research for providing the data for this article. This manuscript formed part of the $\mathrm{PhD}$ thesis of MS Maryam Seyedtabib (No. 9602261248) in Biostatistics, supported by Hamadan University of Medical Sciences.

\section{Ethical Approval}

The Ethics Committee of Hamadan University of Medical Sciences approved this research; with the approval number IR.UMSHA.REC.1396.122, in 2017. The authors assert that all procedures contributing to this work comply with the ethical standards of the relevant national and institutional committees on human experimentation and with the Helsinki Declaration of 1975, as revised in 2008.

\section{Conflict of Interests}

The authors declare that they have no competing interests.

\section{References}

1. Mosher WD, Williams LB, Johnson DP. Religion and fertility in the United States: New patterns. Demography. 1992;29(2):199-214.

2. Mahmood S, Zainab B, Latif AM. Frailty modeling for clustered survival data: an application to birth interval in Bangladesh. J Appl Stat. 2013;40(12):2670-80.

3. Tambi MD. Maternal Participation in Agricultural Production and Population Growth in Cameroon. RAIS J Soc Sci. 2018;2(1):67-88.

4. Liefbroer AC. Changes in family size intentions across young adulthood: A life-course perspective. European journal of population $=$ Revue europeenne de demographie. 2009;25(4):363-86.

5. Adhikari R. Demographic, socio-economic, and cultural factors affecting fertility differentials in Nepal. BMC Pregnancy Childbirth. 2010;10(1):19.

6. Cai Y. China's below-replacement fertility: government policy or socioeconomic development? Population and Development Review. 2010;36(3):419-40.

7. Dribe M, Hacker JD, Scalone F. The impact of socio-economic status on net fertility during the historical fertility decline: A comparative analysis of Canada, Iceland, Sweden, Norway, and the USA. Popul Stud. 2014;68(2):135-49

8. Babalola S, Fatusi A. Determinants of use of maternal health services in Nigeria-looking beyond individual and household factors. BMC Pregnancy Childbirth. 2009;9(1):43.

9. Salehi-Isfahani D, Abbasi-Shavazi MJ, Hosseini-Chavoshi M. Family planning and fertility decline in rural Iran: the impact of rural health clinics. Health Econ. 2010;19(S1):159-80.

10. Uddin M, Bhuyan K, Islam SS. Determinants of desired family size and children ever born in Bangladesh. 2011.

11. Balasch J, Gratacós E. Delayed childbearing: effects on fertility and the outcome of pregnancy. Curr Opin Obstet Gynecol 2012;24(3):187-93.

12. Bumpass LL, Rindfuss RR, Choe MK, Tsuya NO. The institutional context of low fertility: The case of Japan. Asian Popul Stud. 2009;5(3):215-35.

13. Skirbekk V, Samir K. Fertility-reducing dynamics of women's social status and educational attainment. Asian Popul Stud. 2012;8(3):25164.

14. Vithayathil T. Pathways to low fertility in India: Comparison across states and a detailed look at Kerala. Asian Popul Stud. 2013;9(3):30121.

15. Jiang Q, Yang S, Li S, Feldman MW. The decline in China's fertility level: a decomposition analysis. J Biosocial Sci. 2019:1-14.

16. Rutenberg N, Ayad M, Ochoa LH, Wilkinson M. Knowledge and use of contraception. 1991.

17. Dunson DB, Baird DD, Colombo B. Increased infertility with age in men and women. Obstetrics and gynecology. 2004;103(1):51-6.

18. Adsera A. Changing fertility rates in developed countries. The impact of labor market institutions. J Popul Econ. 2004;17(1):17-43.

19. Castles FG. The world turned upside down: below replacement fertility, changing preferences and family-friendly public policy in 21 OECD countries. J Eur Soc Policy. 2003;13(3):209-27.

20. Caldwell BK, Caldwell JC. Below-replacement fertility: Determinants and prospects in South Asia. J Popul Res. 2003;20(1):19-34.

21. Erfani A, McQuillan K. Rapid fertility decline in Iran: analysis of intermediate variables. J Biosocial Sci. 2008;40(3):459-78.

22. Aghajanian A. A new direction in population policy and family planning in the Islamic Republic of Iran. Asia-Pacific population journal. 1995;10(1):3.

23. McDonald P, Hosseini-Chavoshi M, Abbasi-Shavazi MJ, Rashidian A. An assessment of recent Iranian fertility trends using parity progression ratios. Demogr Res. 2015;32:1581-602.

24. Noroozian M. The elderly population in iran: an ever growing concern in the health system. Iran $J$ Psychiatry Behav Sci. 2012;6(2):1.

25. Khamenei SA. Ayatollah Ali Khamenei on Iran's Population Policy. Popul Dev Rev. 2014;40(3):573-5.

26. Islam MR, Islam MR, Alam MR, Hossain MM. Affecting sociodemographic factors on children ever born for women who have experienced domestic violence and women who have not experienced domestic violence in Bangladesh. Am J Sociol Res. 2012;2(5):113-9.

27. Saadati M. Factors affecting children ever born for 15-49 year-old women in Semnan using poisson regression. 2015. 
28. Bbaale E, Mpuga P. Female education, contraceptive use, and fertility: evidence from Uganda. Consilience. 2011(6):20-47.

29. Pasquali R, Pelusi C, Genghini S, Cacciari M, Gambineri A. Obesity and reproductive disorders in women. Hum Reprod Update. 2003;9(4):359-72

30. Sharma R, Biedenharn KR, Fedor JM, Agarwal A. Lifestyle factors and reproductive health: taking control of your fertility. Reprod Biol Endocrinol. 2013;11(1):66.

31. Younglai EV, Holloway AC, Foster WG. Environmental and occupational factors affecting fertility and IVF success. Hum Reprod Update. 2005;11(1):43-57.

32. Yebyo H, Alemayehu M, Kahsay A. Why do women deliver at home? Multilevel modeling of Ethiopian National Demographic and Health Survey data. PLoS One. 2015;10(4):e0124718.

33. Mosher WD, Bachrach CA. Understanding US fertility: continuity and change in the National Survey of Family Growth, 1988-1995. Fam Plann Perspect. 1996;28(1):4-12.

34. Moura-Ramos M, Gameiro S, Canavarro M, Soares I. Assessing infertility stress: re-examining the factor structure of the Fertility Problem Inventory. Hum Reprod. 2011;27(2):496-505.

35. Puts DA, Bailey DH, Cárdenas RA, Burriss RP, Welling LL, Wheatley JR, et al. Women's attractiveness changes with estradiol and progesterone across the ovulatory cycle. Horm Behav. 2013;63(1):13-

36. Lee AH, Wang K, Scott JA, Yau KK, McLachlan GJ. Multi-level zero-inflated Poisson regression modelling of correlated count data with excess zeros. Stat Methods Med Res. 2006;15(1):47-61.

37. Moghimbeigi A, Eshraghian MR, Mohammad K, Mcardle B. Multilevel zero-inflated negative binomial regression modeling for over-dispersed count data with extra zeros. J Appl Stat. 2008;35(10):1193-202.

38. Rashidian A, Karimi-Shahanjarini A, Khosravi A, Elahi E, Beheshtian M, Shakibazadeh E, et al. Iran's multiple indicator demographic and health survey-2010: Study protocol. Int J Prev Med. 2014;5(5):632.

39. Hilbe JM. Negative binomial regression: Cambridge University Press; 2011.

40. Hwang JT. Improving upon standard estimators in discrete exponential families with applications to Poisson and negative binomial cases. Ann Stat. 1982:857-67.

41. Rasbash J, O'Connor T, Jenkins J. Multilevel models for family data. Bristol, England: Centre for Multilevel Modelling, University of Bristol. 2009

42. Amin S, Teerawichitchainan B. Ethnic fertility differentials in Vietnam and their proximate determinants. 2009.

43. Fernández R, Fogli A. Fertility: The role of culture and family experience. J Eur Econ Assoc. 2006;4(2-3):552-61.

44. Islam MM, Dorvlo AS, Al-Qasmi AM. Proximate determinants of declining fertility in Oman in the 1990s. Can Stud Popul. [ARCHIVES]. 2012;38(3-4):133-52.

45. Kohler HP, Rodgers JL, Miller WB, Skytthe A, Christensen K. Bio-social determinants of fertility. Int J Androl. 2006;29(1):46-53.

46. McCrary J, Royer $\mathrm{H}$. The effect of female education on fertility and infant health: evidence from school entry policies using exact date of birth. Am Econ Rev. 2011;101(1):158-95.

47. Poston Jr DL, McKibben SL. Using zero-inflated count regression models to estimate the fertility of US women. J Mod Appl Stat Methods. 2003;2(2):10.

48. Jones GW, Gubhaju B. Factors influencing changes in mean age at first marriage and proportions never marrying in the low-fertility countries of East and Southeast Asia. Asian Popul Stud. 2009;5(3):237-65

49. Benzies K, Tough S, Tofflemire K, Frick C, Faber A, Newburn-Cook C. Factors influencing women's decisions about timing of motherhood. Jognn-J Obst Gyn Neo. 2006;35(5):625-33.

50. Pop-Eleches C. The supply of birth control methods, education, and fertility evidence from Romania. J Hum Resour. 2010;45(4):971-97.

51. Gavin L, Moskosky S, Carter M, Curtis K, Glass E, Godfrey E, et al. Providing quality family planning services: recommendations of CDC and the US Office of Population Affairs. Morb Mortal Wkly Rep: Recommendations and Reports. 2014;63(4):1-54.

52. Bhargava A. Desired family size, family planning and fertility in Ethiopia. J Biosocial Sci. 2007;39(3):367-81.

53. Erfani A, McQuillan K. The changing timing of births in Iran: an explanation of the rise and fall in fertility after the 1979 Islamic
Revolution. Biodemogr Soc Biol. 2014;60(1):67-86.

54. Chowdhury AH, Karim A. Patterns and differentials of birth intervals in Bangladesh. Global Journal of Science Frontier Research Interdisciplinar. 2013;13(2).

55. Kulu H. Why do fertility levels vary between urban and rural areas? Reg Stud. 2013;47(6):895-912.

56. Matsumoto Y, Yamabe S. Family size preference and factors affecting the fertility rate in Hyogo, Japan. Reprod Health. 2013;10(1):6.

57. Ding QJ, Hesketh T. Family size, fertility preferences, and sex ratio in China in the era of the one child family policy: results from national family planning and reproductive health survey. British Medical Journal Publishing Group; 2006;371-373.

58. Hutti MH. Social and professional support needs of families after perinatal loss. J Obstet Gynecol Neonatal Nurs. 2005;34(5):630-8.

59. Satyavada A, Adamchak DJ. Determinants of current use of contraception and children ever born in Nepal. Soc Biol. 2000;47(12):51-60.

60. Barber JS, Axinn WG. New ideas and fertility limitation: The role of mass media. J Marriage Fam. 2004;66(5):1180-200.

61. Hornik R, McAnany E. Theories and evidence: Mass media effects and fertility change. Commun Theory. 2001;11(4):454-71.

62. Rabbi AF. Mass media exposure and its impact on fertility: Current scenario of Bangladesh. J Sci Res. 2012;4(2):383-383.

63. Tarekegn SM, Lieberman LS, Giedraitis V. Determinants of maternal health service utilization in Ethiopia: analysis of the 2011 Ethiopian Demographic and Health Survey. BMC Pregnancy Childbirth. 2014;14(1):161. 